\section{The impact on}

location variables

for the modelling and forecasting of capital expenditure for hyperscale data centres

The objective of the research is to improve accuracy and fill the gap in knowledge to enable the accurate forecasting of the capital expenditure for the construction of hyperscale data centres. This will enable an informed decision on the suitability of the location and the subsequent capital expenditure investment.

/ $₫ 500 m+/-£ 100 m$

/ Uninformed

/ High Risk

$+/-3 \%$ Accuracy $£ 500 \mathrm{~m}+/-£ 15 \mathrm{~m} /$ Informed / Low Risk / Improvement of / $1-2 \%$ on yield

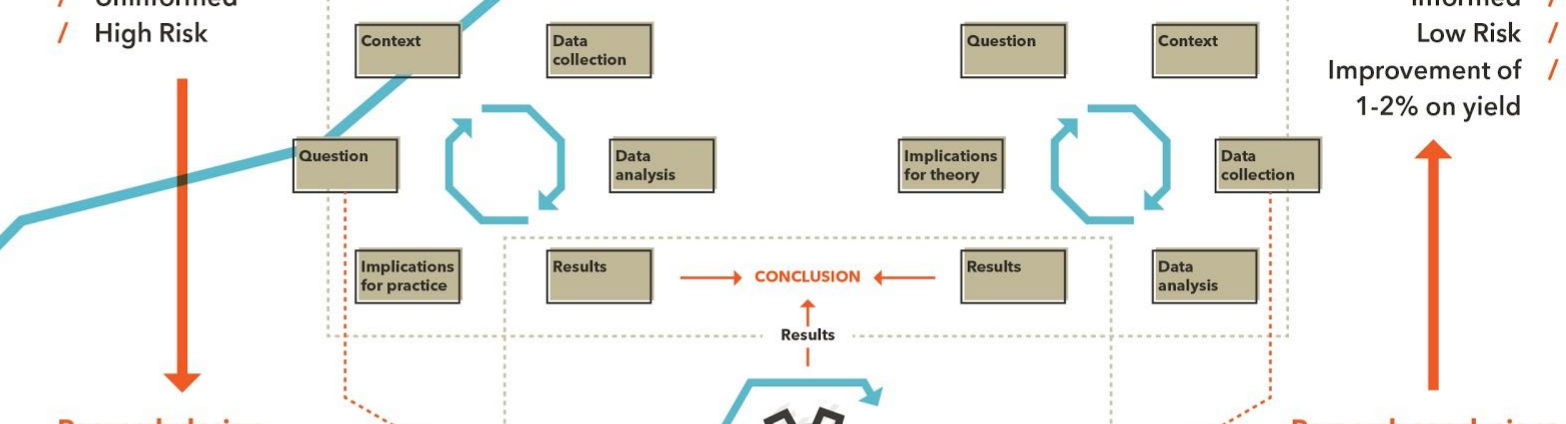

Research design

The research design will likely use a positivist paradigm with a deductive approach, combining predictive theory and action research theory using a multivariate linear regression technique.

The data will be collected using closed questionaires publicly availiable data, industry data and semi structured interviews. This will be analysed in a mixed method approach using both quantitative and qualitative techniques with a cross sectional timeline.
Research conclusions The conclusion is expected to be a model where input location variables are used to predict the capital expenditure for the construction of hyperscale data centres.

This will benefit data centre owners, developers and fund providers when assessing the value of capital expenditure required as a decision for investment in selecting a site location of a hyperscale data centre. 